\title{
Pengaruh Lama Pemasangan Infus dengan Kejadian Flebitis pada Pasien Rawat Inap di Bangsal Penyakit Dalam dan Syaraf Rumah Sakit Nur Hidayah Bantul
}

\author{
Imram Radne Rimba Putri ${ }^{1}$ \\ ${ }^{1}$ Universitas Alma Ata Yogyakarta \\ Jalan Ringroad Barat Daya No 1 Tamantirto, Kasian Bantul Yogyakarta \\ Email:iim_rimba@yahoo.com
}

\begin{abstract}
Abstrak
Pemasangan infus merupakan salah satu prosedur invasif yang dilakukan di rumah sakit. Pasien yang menjalani rawat inap mendapatkan terapi cairan infus dan diberikan secara terus-menerus dalam jangka waktu yang lama akan meningkatkan kemungkinan terjadinya komplikasi dari pemasangan infus, salah satunya adalah terjadinya flebitis. Flebitis didefinisikan sebagai peradangan pada dinding pembuluh darah balik atau vena. Tujuan penelitian ini adalah untuk mengetahui pengaruh antara lama pemasangan infus dengan kejadian flebitis pada pasien di bangsal penyakit dalam dan syaraf Rumah Sakit Nur Hidayah Bantul. Penelitian ini merupakan penelitian observasional analitik dengan pendekatan cross sectional, jumlah sampel ditentukan dengan perhitungan slovin sebanyak 133 orang, dengan teknik pengambilan sampel menggunakan Purposive Sampling. Data hasil dari penelitian ini didapatkan bahwa responden dengan lama pemasangan infus <3 hari sebanyak 37 responden (32,8\%) yang tidak mengalami flebitis 31 responden (10,8\%) dan yang mengalami flebitis 6 responden (26,2\%). Sedangkan untuk responden dengan lama pemasangan infus $\geq 3$ hari sebanyak 76 responden $(67,2 \%)$ yang mengalami flebitis 74 responden $(53,8 \%)$ dan yang tidak mengalami flebitis 2 responden (22,2\%). Berdasarkan hasil analisis data dengan menggunakan uji Chi Square didapatkan nilai p-value sebesar 0,000, yang berarti nilai signifikan lebih kecil dari taraf signifikan $\alpha$ : 0,05, itu berarti hipotesis penelitian ini diterima. Kesimpulannya bahwa ada pengaruh lama pemasangan infus terhadap kejadian flebitis. Oleh karena itu dapat disarankan untuk tim kesehatan di rumah sakit untuk melakukan perawatan infus pasien sesuai prosedur, terutama untuk pasien dengan pemasangan infus lebih dari 3 hari, untuk menghindari terjadinya flebitis.
\end{abstract}

Kata Kunci: infus, lama pemasangan infus, flebitis

\section{The Effect of Infusion Duration with The Incidence of Phlebitis in Patients at Internal Medicine Wards and Nerves Hospital Nur Hidayah Bantul}

\begin{abstract}
Infusion is one invasive procedure performed in a hospital. Inpatient therapy and intravenous fluids are given continuously in the long term will increase the likelihood of complications from infusion, one of which is the occurrence of phlebitis. The purpose of this study was to determine the effect of treatment duration infusion with the incidence of phlebitis in patients on the ward and neurological disease in the Nur Hidayah hospital in Bantul. This research is an analytic observational study with cross sectional approach, the number of samples is determined by calculation slovin as many as 133 people, with the sampling technique used purposive sampling. Data results from this study showed that respondents with a longer infusion $<3$ days a total of 37 respondents (32.8\%) who did not have phlebitis 31 respondents (10.8\%) and those with phlebitis 6 respondents (26.2\%). As for respondents with a longer infusion $\geq 3$ days as many as 76 respondents (67.2\%) who experienced phlebitis 74 respondents (53.8\%) and who had not had phlebitis 2 respondents (22.2\%). Based on the results of data analysis using chi-square test values obtained p-value of 0.000 , which means the value significantly smaller than the significance level $\alpha: 0.05$, it means that the research hypothesis is
\end{abstract}


accepted. In conclusion, that there is a long infusion influence on the incidence of phlebitis. Therefore, it may be advisable for the health care team in a hospital for treatment of patients infusion according to the procedure, especially for patients with infusion of more than 3 days, to avoid the occurrence of phlebitis.

Keywords: infusion, infusion installation, phlebitis

Info Artikel:

Artikel dikirim pada 20 Mei 2016

Artikel diterima pada 23 Juni 2016

DOI : http://dx.doi.org/10.21927/jnki.2016.4(2).90-94

\section{PENDAHULUAN}

Pemasangan infus merupakan prosedur invasif yang sering dilakukan di rumah sakit untuk mengobati berbagai kondisi penderita di lingkungan perawatan rumah sakit. Pasien yang menjalani rawat inap mendapatkan terapi cairan infus dan diberikan secara terus-menerus dalam jangka waktu yang lama akan meningkatkan kemungkinan terjadinya komplikasi dari pemasangan infus, salah satunya adalah infeksi (1). Infeksi nosokomial atau Hospital Acquired Infection (HAls) pada pasien yang mendapat terapi infus merupakan salah satu indikator adanya infeksi akibat kesalahan pemasangan atau pemasangan infus yang tidak sesuai prosedur terutama masalah teknik septik-aseptik. Suatu penelitian yang dilakukan oleh WHO menunjukkan bahwa sekitar $8,7 \%$ dari 55 rumah sakit dari 14 negara yang berasal dari Eropa, Timur Tengah, Asia Tenggara dan Pasifik menunjukkan adanya infeksi nosokomial Hospital Acquired Infection (HAls) dan untuk Asia Tenggara sebanyak $10,0 \%$ (2).

Flebitis didefinisikan sebagai peradangan pada dinding pembuluh darah balik atau vena (3). Flebitis yaitu infeksi oleh mikroorganisme yang dialami oleh pasien yang diperoleh selama dirawat di rumah sakit diikuti dengan manifestasi klinis yang muncul sekurang-kurangnya $3 \times 24$ jam. Kejadian flebitis menjadi salah satu indikator mutu pelayanan rumah sakit dengan standar yang ditetapkan oleh The Infusion Nursing of Practice yaitu 5\% (4). Data insidensi flebitis di Indonesia secara nasional belum ditemukan namun hasil penelitian terdahulu di Rumah Sakit Umum Daerah Tugurejo Semarang menunjukkan bahwa angka kejadian flebitis di rumah sakit tersebut sebesar $51,2 \%$, yang berarti angka tersebut tergolong tinggi (5). Flebitis dapat menjadi bahaya, karena bekuan darah atau tromboflebitis bisa menyebabkan emboli, hal ini dapat menimbulkan kerusakan permanen pada vena. Kejadian flebitis meningkat sesuai dengan lamanya infus terpasang, dari kejadian tersebut dapat mengakibatkan pasien menjalani perawatan yang lebih lama sehingga pasien harus mengeluarkan biaya yang lebih banyak (1).

Setelah dilakukan studi pendahuluan di Instalansi Rawat Inap Rumah Sakit Nur Hidayah Yogyakarta oleh peneliti didapatkan data dari Tim PPI Rumah Sakit Nur Hidayah menunjukkan bahwa jumlah pasien Rawat inap yang dilakukan pemasangan infus 4 bulan terakhir sebanyak 2.185 pasien dan yang mengalami flebitis sebanyak 8 $(0,5 \%)$ sedangkan pada bulan Agustus pasien yang dilakukan pemasangan infus sebanyak 474 pasien dan yang mengalami flebitis sebanyak 2 $(0,6 \%)$. Presentase kejadian tersebut menurut standar indikator mutu pelayanan minimal rumah sakit dapat dikatakan sesuai bahkan lebih rendah dengan standar kejadian $\leq 1,5 \%$ (4), namun data tersebut tidak sesuai dengan hasil wawancara yang dilakukan terhadap perawat pelaksana di Bangsal Penyakit Dalam \& Saraf dan Bangsal Bedah yang mengatakan bahwa data kejadian flebitis 3-5 pasien tiap bulan. Dengan demikian dapat dikatakan bahwa data yang berasal dari tim PPI RS Nur Hidayah kurang valid dan bisa saja angka kejadian flebitis di RS tersebut lebih tinggi dari data yang di dapat tim PPI.

Hal tersebut dapat menjadi perhatian khusus karena salah satu indikator mutu akreditasi KARS 2012 adalah angka kejadian infeksi rumah sakit (HAls), dan salah satu indikator angka kejadian infeksi adalah angka kejadian flebitis di Rumah Sakit. Berdasarkan latar belakang diatas peneliti tertarik untuk melakukan penelitian tentang pengaruh lama perawatan infus dengan kejadian flebitis pada pasien di bangsal penyakit dalam dan syaraf Rumah Sakit Nur Hidayah Bantul. 


\section{BAHAN DAN METODE}

Desain dalam penelitian ini menggunakan penelitian observasional analitik dengan pendekatan cross sectional yang digunakan untuk pengaruh lama perawatan infus dengan kejadian flebitis pada pasien di bangsal penyakit dalam dan syaraf Rumah Sakit Nur Hidayah Bantul. Populasi dalam penelitian ini adalah semua pasien yang terpasang infus di bangsal penyakit dalam dan syaraf Rumah Sakit Nur Hidayah Bantul, dengan jumlah sampel ditentukan dengan perhitungan Slovin sebanyak 133, dengan teknik pengambilan sampel menggunakan purposive sampling. Pengumpulan data dilakukan dengan menggunakan lembar observasi yang dinilai dengan Infusion Phlebitis Score (4). Analisa data yang digunakan menggunakan analisa univariat dan analisa bivariat dengan uji chi-square.

\section{HASIL DAN BAHASAN}

\section{Distribusi Responden Berdasarkan Lama Pemasangan Infus}

Distribusi frekuensi responden berdasarkan lama pemasangan infus di Bangsal Penyakit Dalam dan Syaraf Rumah Sakit Nur Hidayah Bantul disajikan dalam Tabel 1.

Tabel 1. Distribusi Responden Berdasarkan Lama Pemasangan Infus di Bangsal Penyakit Dalam dan Syaraf Rumah Sakit Nur Hidayah Bantul

\begin{tabular}{lcc}
\hline Lama Pemasangan Infus & $\mathbf{f}$ & \% \\
\hline$<3$ hari & 37 & 32,8 \\
$\geq 3$ hari & 76 & 67,2 \\
Total & 113 & 100 \\
\hline
\end{tabular}

Sumber: Data Primer Tahun 2016

Berdasarkan Tabel 1 menjelaskan bahwa hasil penelitian ini sebagian besar responden dirawat inap $\geq 3$ hari yaitu sebanyak 76 responden dengan persentase $67,2 \%$. Lama pemasangan infus dapat mempengaruhi terjadinya infeksi salah satunya adalah flebitis, hal ini dikarenakan pada saat pasien terpasang infus berarti kita seperti memasukan benda asing kedalam tubuh pasien, semakin lama terpasang infus maka dapat menimbulkan infeksi. Karena pada saat terpasang infus akan menyebabkan trauma sehingga mikroorganisme yang menyebabkan flebitis dapat dengan mudah masuk, terlebih pada saat pemasangan infus tidak dilakukan sesuai SOP, begitupula dengan perawatan infus yang tidak sesuai SOP akan menjadi salah satu faktor yang sangat mempengaruhi terjadinya flebitis.

Pasien dengan tindakan infus lebih dari 3 hari berisiko terkena infeksi nosokomial bila dibandingkan dengan pasien yang menggunakan infus kurang dari 3 hari, hal tersebut dikarenakan lokasi penusukan/ insersi infus yang lebih dari 3 hari akan menyebabkan organisme flora normal tumbuh secara berlebih sehingga menyebabkan infeksi (6). Senada dengan penelitian terdahulu dengan judul Hubungan Lama Pemasangan Infus (Intravena) Dengan Kejadian Flebitis pada Pasien di Irna F Blu RSUP Prof. Dr. R. D. Kandau Manado, didapatkan angka kejadian flebitis dalam waktu pemasangan infus lebih dari 72 jam sebesar $27,6 \%$ (7). Karena pada saat terpasang infus tubuh beresiko terkontaminasi dengan mikroorganisme, terlebih penggunaan keteter intravena dalam ja ngka waktu yang lama, tanpa dilakukan rotasi penusukan setiap 72 jam, hal ini dapat menyebabkan terjadinya flebitis.

\section{Distribusi Responden Berdasarkan Kejadian Flebitis}

Distribusi frekuensi responden berdasarkan kejadian Flebitis di Bangsal Penyakit Dalam dan Syaraf Rumah Sakit Nur Hidayah Bantul disajikan dalam Tabel 2.

Tabel 2. Distribusi Responden Berdasarkan Kejadian Flebitis di Bangsal Penyakit Dalam dan Syaraf Rumah Sakit Nur Hidayah Bantul.

\begin{tabular}{ccc}
\hline Kejadian Flebitis & $\mathbf{f}$ & \% \\
\hline Flebitis & 80 & 70,8 \\
Tidak flebitis & 33 & 29,2 \\
Total & 113 & 100 \\
\hline
\end{tabular}

Sumber: Data Primer Tahun 2016

Berdasarkan Tabel 2 menjelaskan bahwa hasil penelitian ini sebagian besar responden mengalami flebitis yaitu 80 responden dengan persentase $70,8 \%$ dibandingkan dengan yang tidak mengalami flebitis yaitu 33 responden dengan persentase $29,2 \%$.

Kejadian flebitis diketahui dengan cara mengobservasi lokasi insersi atau tusukan infus dengan melihat adanya tanda dan gejala flebitis yang meliputi nyeri sepanjang kanul, eritema atau kemerahan pada lokasi insersi, demam pada tempat penusukan, adanya indurasi dan vena cord teraba (6). Berdasarkan hasil tersebut di atas dapat dikatakan angka flebitis di ruang rawat inap sangat tinggi melebihi standar yang ditetapkan oleh Intravenous 
Nurses Society (INS) 5\% (4). Hal ini dikarenakan perawatan infus dilakukan tidak sesuai dengan teori yang seharusnya. Hal ini didukung dengan ruang rawat inap yang jarang dilakukan sterilasi dan masih kurangnya kesadaran perawat dalam melakukan cuci tangan sebelum melakukan tindakan sehingga meningkatkan angka HAl's di bangsal tersebut.

Flebitis merupakan peradangan pada dinding pembuluh darah balik atau vena dan kejadiannya meningkat sejalan dengan lamanya kanulasi atau waktu pemasangan (8). Hasil penelitian ini didukung penelitian terdahulu yang berjudul kejadian flebitis di Rumah Sakit Umum Daerah Majalaya dengan hasil dari 90 responden yang diobservasi $32,2 \%$ mengalami flebitis dan $67,8 \%$ tidak mengalami flebitis dan dari hasil uji chi-square dan coeffisient contingenci didapatkan hasil bahwa ada hubungan yang bermakna antara faktor resiko pemasangan infus dengan $p$-value sebesar 0,031 , faktor usia dengan $p=0,000$ dan status gizi pasien dengan $p=0,007$ dengan kejadian flebitis (9).

\section{Pengaruh Lama Pemasangan Infus dengan Kejadian Flebitis}

Hubungan lama pemasangan infus dengan kejadian Flebitis di Bangsal Penyakit Dalam dan Syaraf Rumah Sakit Nur Hidayah Bantul disajikan dalam Tabel 3.

Tabel 3. Pengaruh Lama Pemasangan Infus dengan Kejadian Flebitis di Bangsal Penyakit Dalam dan Syaraf Rumah Sakit Nur Hidayah Bantul

\begin{tabular}{|c|c|c|c|c|c|c|c|}
\hline \multirow{3}{*}{$\begin{array}{l}\text { Lama } \\
\text { Pemasangan } \\
\text { Infus }\end{array}$} & \multicolumn{6}{|c|}{ Kejadian Flebitis } & \multirow{3}{*}{ p-value } \\
\hline & \multicolumn{2}{|c|}{$\begin{array}{c}\text { Tidak } \\
\text { Flebitis }\end{array}$} & \multicolumn{2}{|c|}{ Flebitis } & \multicolumn{2}{|c|}{ Total } & \\
\hline & $\mathbf{n}$ & $\%$ & $\mathbf{n}$ & $\%$ & $\mathbf{n}$ & $\%$ & \\
\hline$<3$ hari & 31 & 10,8 & 6 & 26,2 & 37 & 32,8 & \\
\hline$\geq 3$ hari & 2 & 22,2 & 74 & 53,8 & 76 & 67,2 & 0.00 \\
\hline Total & 33 & 29,2 & 80 & 70,8 & 113 & 100 & \\
\hline
\end{tabular}

Sumber: Data Primer Tahun 2016

Berdasarkan Tabel 3 terdapat 2 kategori yaitu lama pemasangan infus dan kejadian flebitis. Tabel di atas menjelaskan bahwa responden dengan lama pemasangan infus $<3$ hari sebanyak 37 responden $(32,8 \%)$ yang tidak mengalami flebitis 31 responden $(10,8 \%)$ dan yang mengalami flebitis 6 responden $(26,2 \%)$. Sedangkan untuk responden dengan lama pemasangan infus $\geq 3$ hari sebanyak 76 responden $(67,2 \%)$ yang mengalami flebitis 74 responden $(53,8)$ dan yang tidak mengalami flebitis 2 responden $(22,2 \%)$.

Berdasarkan hasil analisis data dengan menggunakan uji chi-square didapatkan nilai $p$-value sebesar 0,000 , yang berarti nilai signifikan lebih kecil dari taraf signifikan $5 \%$ atau nilai $p$-value $=0,000$ lebih kecil dari 0,05 , maka dapat dinyatakan ada pengaruh lama pemasangan infus terhadap kejadian flebitis, Sehingga menjawab hipotesis dalam penelitian ini yaitu adanya pengaruh antara lama pemasangan infus pada pasien rawat inap di bangsal penyakit dalam dan syaraf Rumah Sakit Nur Hidayah Bantul.

Hasil dari penelitian ini sejalan dengan penelitian terdahulu yang berjudul hubungan lamanya pemasangan infus (intravena) dengan kejadian flebitis pada pasien di Irina F Blu Rsup Prof. Dr. R. D. Kandou Manado yang analisis datanya dilakukan dengan menggunakan uji chi-square, pada tingkat kemaknaan $95 \%(\alpha 0,05)$ menunjukkan nilai $p=0,000$, nilai ini lebih kecil dari $\alpha=0,05$. Sehingga dapat dinyatakan bahwa terdapat hubungan lamanya pemasangan infus (intravena) dengan kejadian flebitis pada pasien di Irina F Blu RSUP Prof. Dr. R. D. Kandou Manado (7).

Hasil penelitian ini juga terdapat data yang menunjukkan bahwa ada 6 pasien yang sudah mengalami flebitis sebelum lama pemasangan infus tiga hari. Berdasarkan hasil observasi peneliti yang dilakukan ditempat penelitian, hal tersebut dapat terjadi dikarenakan bahwa kejadian flebitis pada pasien rawat inap di bangsal penyakit dalam dan syaraf Rumah Sakit Nur Hidayah tidak hanya dipengaruhi oleh lamanya terpasang infus pada pasien, akan tetapi kejadian flebitis juga di pengaruhi oleh perawatan infus, jenis terapi injeksi dan terapi cairan yang diberikan. Hasil analisa tersebut didukung oleh penelitian terdahulu yang berjudul hubungan perawatan infus dengan kejadian flebitis pada pasien yang terpasang infus di puskesmas Krian Sidoarjo menyatakan bahwa dari 20 responden $12(60 \%)$ di lakukan sebagaian besar perawatan infus, $2(10 \%)$ dilakukan semua perawatan infus, $2(10 \%)$ tidak di lakukan perawatan infus. Sedangkan 20 responden sebanyak 14 (70\%) tidak terjadi flebitis, $6(30 \%)$ terjadi flebitis. Dari hasil uji spearman's rho diperoleh nilai $p$-value 0,000 karena $p$-value $<0,05$, hal ini berarti ada hubungan signifikan antara perawatan infus dengan kejadian flebitis (10). Hal tersebut sesuai dengan teori yang menjelaskan bahwa banyak faktor penyebab flebitis antara lain; tehnik cuci tangan yang tidak baik saat pemasangan atau pun perawatan infus, tehnik aseptik yang kurang 
baik pada saat penusukan, teknik penusukan yang kurang tepat, pemasangan yang terlalu lama dan jenis terapi atau cairan yang masuk melalui kateter infus (11).

\section{SIMPULAN DAN SARAN}

Berdasarkan hasil dan bahasan dapat disimpulkan bahwa sebagian besar responden di bangsal penyakit dalam dan syaraf rumah sakit Nur Hidayah Bantul adalah $\geq 3$ hari, yaitu sebanyak 76 responden dengan persentase $67,2 \%$, sebagian besar responden mengalami flebitis yaitu 80 responden dengan persentase $70,8 \%$ sedangkan yang tidak mengalami flebitis yaitu 33 responden dengan persentase $29,2 \%$. Ada pengaruh antara lama pemasangan infus pada pasien rawat inap di bangsal penyakit dalam dan syaraf Rumah Sakit Nur Hidayah Bantul.

Disarankan untuk tim kesehatan di rumah sakit terutama perawat dalam melakukan perawatan infus sebaiknya dilakukan setiap hari atau sesuai dengan prosedur perawatan infus yang sesuai. Terutama untuk pasien dengan pemasangan infus lebih dari 3 hari. Sejak awal pemasangan infus juga dilakukan sesuai prosedur. Serta perlunya koordinasi dengan bagian sanitasi untuk melakukan penjadwalan seterilisasi ruangan. Serta peningkatan kesadaran tim kesehatan dalam melakukan cuci tangan 6 langkah atau sesuai SPO sebelum melakukan tindakan terutama yang terpapar langsung dengan pasien sehingga dapat menurunkan angka flebitis Rumah Sakit Nur Hidayah Bantul.

\section{RUJUKAN}

1. Hinlay. Terapi Intravena pada pasien di Rumah Sakit. Yogyakarta: Nuha Medika; 2006.
2. World Health Organization. WHO 2007 Word alliance of patient safety and ,WHO Guidelines on hand hygiene in health care advanced draft, Asummary cleans hands. 2015.

3. Darmadi. Infeksi nosokomial. Problematika dan pengendaliannya. Jakarta: Salemba Medika; 2008.

4. Alexander M, Corrigan A, Gorski L, RN, MS, C, et al. Infusion Nursing: An Evidence Based Approach. Alexander M, editor. Saunders Elsevier Inc; 2010.

5. Indraningtyas. Hubungan Lama Pemasangan Infus dengan kejadian Flebitis Di RSUD Tugurejo Semarang. Semarang; 2013.

6. Potter PA, Perry AG. Fundamentals of Nursing. 7th ed. Elsavier; 2010.

7. Cristian MK, Lucky K, Franly O. Hubungan lama pemasangan Hubungan Lama Pemasangan Infus (Intravena) dengan Kejadian Flebitis pada Pasien di Irina F Blu RSUP Prof. Dr. R. D. Kandau Manado. Manado; 2014.

8. Gabriel J, Bravery K, Dougherty L, Kayley J, Malster M, Scales K. Vascular access: indications and implications for patient care. Nurs Stand [Internet]. 19(26):45-52. Available from: http:// www.ncbi.nlm.nih.gov/pubmed/15789996

9. Prastika D, Susilaningsih FS, Amir A. Kejadian Flebitis di Rumah Sakit Umum Daerah Majalaya. students e-journals. 2012;1(1):1-11.

10. Aprilin $H$. Hubungan Perawatan Infus denganTerjadinya Flebitis pada Pasien yang Terpasang Infus di Puskesmas Krian Sidoarjo. J Keperawatan. 2011;1.

11. Makary MA, Sexton JB, Freischlag JA, Millman EA, Pryor D, Holzmueller C, et al. Patient safety in surgery. Ann Surg [Internet]. 2006 May;243(5):628-32; discussion 632-5. Available from: http://www.ncbi.nlm.nih.gov/ pubmed/16632997 